\section{Attachment to shifting cultivation among Konyak Naga tribe in Eastern Himalaya: choice or compulsion?}

\author{
D. K. Pandey ${ }^{1, *}$, P. Adhiguru ${ }^{2}$ and H. K. De ${ }^{3}$ \\ ${ }^{1}$ Central Agricultural University (I), Pasighat 791 102, India \\ ${ }^{2}$ Krishi Anusandhan Bhavan-I, Pusa, New Delhi 110 012, India \\ ${ }^{3}$ ICAR-Central Institute of Freshwater Aquaculture, \\ Bhubaneswar 751002 , India
}

Community attachment to places or practices and the cultural contexts of tribes are subjects of long traditions of research. A few studies, however, have extended these traditions into increasingly marginalized areas located beyond historically deprived upland communities. This study addresses issues related to the sentiments of attachment and constructions of place among the low-income Konyak Naga tribe in Nagaland, situated on the outer fringes of the Eastern Himalaya. Using four-dimensional model proposed by Raymond et al., with factor analysis, the study revealed that in addition to socio-economic factors that affect such connection to land and landscape, place dependence construct (lack of alternate livelihood) is observed to be the most important driver of attachment to the practice of shifting cultivation. This was followed by strong connections with the natural environment or nature bonding of Konyak Naga to the forest. Contribution of economic and traditional institution-bonding with the practice was found among the tribe as a means of livelihood. Sensing that such debate of the socio-spatial environment might be perceived as inconsistent, ill-informed and negative, we discuss implications in relation to cultural diversity and broader concerns about evolving rural poverty.

Keywords: Factorial analysis, place attachment model, shifting cultivation, tribal communities.

MANY of India's native tribes and cultures in far-flung areas of the country still follow practices handed down from their ancestors. The Konyaks are the largest among the 16 tribes inhabiting Nagaland in North East India. Located in the mountainous regions, they spread across Nagaland and Arunachal Pradesh in India, and also in Myanmar ${ }^{1}$. The Konyaks are still ruled by hereditary chieftains known as Anghs. Naga farmers adopt an age-old conventional farming system called shifting cultivation (SC) (jhuming), where a land is selected for cultivation for 1 or 2 years and thereafter left abandoned for numerous years. About $73 \%$ of people in Nagaland are dependent on agriculture and most of them are involved in SC, because of the compulsion of its natural hilly topography and traditional method of farming ${ }^{2}$. Being one of the major means of land uses in the state, the prac-

\footnotetext{
*For correspondence. (e-mail: dkpextension@gmail.com)
}

tice of SC involved 135,339 rural households covering about $947.37 \mathrm{sq}$. km. This, in turn, constitutes $5.71 \%$ of the total geographic area of the state ${ }^{3}$. As such, the controversial practice of SC in Southeast Asia has a long history, which ensures food security and is the main source of livelihood for many uplanders in the region. As there is growing evidence of the socio-cultural value, livelihood and food security, and ecosystem service of SC, the National Institution for Transforming India, a policy think-tank of the Government of India has recently recognized this practice positively ${ }^{4}$. Regardless of their diversity, most of the tribal people in NE India are deeply attached to their lands and produce food for selfsufficiency through SC, consequently ensuring food security. This method of farming is their way of life, rather than merely a farming technique for indigenous peoples in Asia ${ }^{5}$. Some studies suggest that SC fallow systems constitute 'living landscapes', where multi-functional connections between land, forest and farm support human well-being and ecosystem services ${ }^{6}$. Recognizing such values and interests, the Sixth Schedule of the Indian Constitution provided the tribal people of NE India, a role in designing the development of their land. This was to ensure that the development happens free of external influences or pressures, and also in accordance with the local traditions and needs ${ }^{7}$.

Despite the growing recognition of SC (with long fallow) in contributing to supporting ecosystem services and livelihood security, most international, regional and national policies, particularly in Southeast Asia, continue to press for its replacement with other land uses ${ }^{8,9}$. Most of the governments have been trying to ban SC while tribals struggle to practice it, sometimes even illegally. Throughout the Eastern Himalayan region, this practice continues over large areas and contributes to livelihood security and ecosystem services for many poor uplanders in Southeast Asia today ${ }^{10}$. In such a divergent situation in terms of perspectives towards SC, focus on developing understanding towards both attachment to a place and a practice can help clarify opportunities and obstacles for collaborations between different interest groups which in turn can effectively influence stewardship and transformative capacity related to SC.

Attachment to any place or practice is a bond of human emotion, not only with the physical setting of the place, but also with the people and their lifestyle ${ }^{11}$. In fact, attachment to a place emerges through personal experience with the environment and consists of two related dimensions: place dependence and place identity ${ }^{12}$. Place dependence conveys an instrumental connection between people and place, conceived and measured as the ability of a setting to facilitate goal achievement and to satisfy important needs. It also refers to functional features of a place that facilitate certain activities and emotional connections $^{13}$. Using place attachment construct and associated dimensions, the present study helps bridge 
Table 1. Factorial analysis for sustenance of shifting cultivation among Konyaks towards livelihood

\begin{tabular}{|c|c|c|c|c|c|}
\hline Item & $\begin{array}{l}\text { Factor } \\
\text { loading }\end{array}$ & $\begin{array}{l}\text { Grand } \\
\text { mean }\end{array}$ & $\begin{array}{l}\text { Item } \\
\text { mean }\end{array}$ & $\begin{array}{l}\text { Standard } \\
\text { deviation }\end{array}$ & $\begin{array}{l}\text { Cronbach } \\
\text { alpha }\end{array}$ \\
\hline Economic bonding (eigenvalue $=3.19 ;$ variance explained $=79.74 \%$ ) & & 4.22 & & & 0.82 \\
\hline Tribals have better access to timber resources & 0.98 & & 4.72 & 0.45 & \\
\hline $\begin{array}{l}\text { Nowadays, in SC, commercially oriented crops are more preferred to } \\
\text { subsistence-based food crops }\end{array}$ & 0.99 & & 3.64 & 1.08 & \\
\hline Non-timber-based forest products (NTFP) fetch more income from the SC land & 0.99 & & 3.86 & 0.67 & \\
\hline $\mathrm{SC}$ is a major source of food security for tribals & 0.99 & & 4.64 & 0.48 & \\
\hline Traditional institution bonding (eigenvalue $=0.68 ;$ variance explained $=16.93 \%$ ) & & 3.50 & & & 0.73 \\
\hline $\begin{array}{l}\text { The collective process of decision-making is not observed in } \\
\text { managing SC land resources }\end{array}$ & 0.93 & & 2.88 & 1.21 & \\
\hline $\begin{array}{l}\text { Even now for SC, the exchange of labour among family members is practised } \\
\text { like in ancient times }\end{array}$ & 1.00 & & 4.44 & 0.61 & \\
\hline The customary laws are not as strong as those in the past & 0.84 & & 3.02 & 0.91 & \\
\hline $\begin{array}{l}\text { The present generation does not manage SC resources well like its } \\
\text { forefathers }\end{array}$ & 0.98 & & 2.78 & 1.28 & \\
\hline The common property land tenure regime is best for SC maintenance & 1.00 & & 3.44 & 0.81 & \\
\hline Nature bonding (eigenvalue $=0.12 ;$ variance explained $=2.89 \%)$ & & 3.96 & & & 0.85 \\
\hline $\mathrm{SC}$ activity is laborious compared to settled cultivation & 0.99 & & 4.54 & 0.65 & \\
\hline Tribals have abundant SC land & 1.00 & & 3.22 & 1.23 & \\
\hline $\mathrm{SC}$ is greatly affected through climate change & 0.9 & & 4.08 & 0.57 & \\
\hline $\begin{array}{l}\text { The failure of one crop in SC is not a problem, as tribals grow a variety } \\
\text { of food crops }\end{array}$ & 0.92 & & 4.00 & 0.45 & \\
\hline Lack of alternate occupation (eigenvalue $=0.02 ;$ variance explained $=0.44 \%$ ) & & 3.16 & & & 0.91 \\
\hline There is no livelihood opportunity apart from SC & 0.90 & & 3.44 & 1.01 & \\
\hline Tribals do not have knowledge to pursue non-SC activity & 0.96 & & 2.72 & 1.25 & \\
\hline Off-farm opportunities of high income may force tribals move away from SC & 0.96 & & 3.28 & 0.90 & \\
\hline $\begin{array}{l}\text { Absence of good employment opportunities in the village forces the younger } \\
\text { generation to continue ancestral occupation of SC }\end{array}$ & 1.00 & & 3.20 & 1.11 & \\
\hline
\end{tabular}

such empirical knowledge gap in community resource management and drivers of SC persistence.

Covering a study sample of 90 tribal households during 2016-17 from Mon district, Nagaland, which borders Myanmar, we adopted place attachment method proposed by Raymond et al. ${ }^{14}$. The model includes economic bonding (livelihood connections/dependence to place), nature bonding (connections to the natural environment), and traditional institution/social bonding (connections to the community in a place) and lack of alternative occupation. The items were rated on a 5-point Likert scale, ranging from 1 ('strongly disagree') to 5 ('strongly agree'). For negatively worded items, scoring was reversed. Factor analysis was used to determine the validity of the attachment scale. The summated scale analysed the items to total and inter-item correlations between the place attachment items. The items rating was then subjected to exploratory factor analysis (principal component analysis (PCA) with varimax rotation), as enunciated by Pearson $^{15}$. The criterion used by Hammitt et al. ${ }^{16}$ was followed in forming factors, i.e. eigenvalue $\geq 1.0$, factor loading $\geq 0.40$.

PCA and reliability analysis of responses to the 18point place attachment scale indicated four underlying dimensions with high reliabilities (Table 1, Cronbach alpha $>0.70$ or higher) were considered.

The eigenvalue shows the importance of each of the principal components. Only the first three factors have eigenvalues greater than 1.00, and together they explain over $79.74 \%$ of the total variability in the data (Table 1 ). This led us to the conclusion that a factor solution will probably be adequate. In bonding analysis, three validated dimensions were studied, viz. economic bonding, traditional bonding and nature bonding. Four items were found to be related with economic bonding, followed by six items with traditional institutional bonding and further four items related to nature bonding loaded on a naturebonding dimension with high reliability (Crobach alpha $>0.90$ ). The scale item, 'Non-timber based forest products (NTFP) fetch more income from the SC land' loaded less strongly on economic bonding dimension than other measures of economic bonding. However, this scale was still significant and contributed strongly (factor loading $>0.88$ ). Traditional institutional bonding emerged as a more efficient dimension with a maximum of six dimension scales. Six items loaded strongly on this dimension.

A scree plot displays the eigenvalues associated with a component or factor in descending order versus number 
of the component or factor (Figure 1). The eigenvalues in Table 1 indicate that the first value accounts for $79.74 \%$ of the variation and the second value for $16.93 \%$, making a total of $96.67 \%$ of the total variation. The third value only explains $3.23 \%$ of the variation, and contributions from the remaining eigenvalues are negligible.

Besides, contribution of sense of place to sustenance of $\mathrm{SC}$, the other vital factors responsible for persistence of SC were determined with 3-point Likert scale using focused group discussions and key informant interviews in the study area. While underpinning the drivers by the respondents that compels them to continuously depend on $\mathrm{SC}$, it is observed that besides biophysical property of forest land, the 'common property' nature of land affects decision-making process to go for settled cultivation. Figure 2 presents factors governing attachment to SC.

The figure reveals that among several bottlenecks, lack of supportive infrastructure, particularly road connectivity and market facilities ( $x=2.63)$, paucity of low-cost sloping agricultural land technology $(x=2.44)$ and absence of agricultural extension/advisory services $(x=2.30)$ emerge as the most important challenges that hinder the different options of livelihood diversification. Further, unavailability of credit facilities due to 'common property' nature of SC land is a vital impediment as expressed by the respondents towards diversification of their livelihood and income enhancement by adopting alternative occupations.

The present study revealed that in Mon district, people seem to be highly dependent on forest landscape for their survival. The place attachment concept allowed us to understand this dependency and explain the persistence of SC. In fact, the study emphasized the importance of economic factors and the lack of alternative solutions as a factor of place attachment among tribals. It suggested that access to timber resources and food were predominant variables; and that SC guarantees economic security. In Mon district, with abject poverty (48\%), lowest HDI $(0.50)$ and low ranking in terms of changes in HPI index ${ }^{17}$, attachment to SC and forests is more discernible. Forests and culture system are essential for livelihood and subsistence income ${ }^{18}$. Economic factors and place dependence seem to influence each other. As suggested, poverty leads on strong dependency on forest activities, which sustain $\mathrm{SC}^{19}$. Also, places that provide income to the residents influence place attachment ${ }^{20}$. Nowadays, SC seems to be the only source of livelihood for the tribal population. In fact, in the study, the tribals expressed the lack of other opportunities to ensure food security of their household. There was absence of off-farm employment ${ }^{7,21}$, and other employment opportunities in the villages. Therefore, due to other necessity, tribal populations continue their traditional practices, including SC. For example, the Supreme Court of India has banned timber extraction and coal mining in forest areas; hence, cultivators have returned to SC practices and have also resorted to illegal practices like charcoal making (Meghalaya), and poppy and cannabis cultivation (Manipur) for cash ${ }^{4}$. Therefore, tribals not only prefer to live nearby forest areas but due to their higher dependency on natural resources and poor and backward technology ${ }^{22}$, they have recourse to $\mathrm{SC}$.

Beyond economic criteria and livelihood, nature bonding and traditional institution bonding are significant factors of place attachment among tribal. Beyond survival goals, nature is part of the daily life of tribals. There is a strong connection between tribal populations and nature. This nature-man connection is rooted in their lifestyle and culture. Plants and trees in the tribal areas are considered sacred $^{23}$; therefore, tribals consider it as their duty to conserve the natural world ${ }^{24}$. For example, people of Garo hills have used their traditional ecological knowledge to manage their lands with long fallow system. Such SC is generally sustainable and is the best cropping method in areas where flat land is not available ${ }^{24}$. Moreover, according to tribal farmers, despite climate change and its effects, their systems generate sufficient resources since they are varied. Nature is part of tribal daily life, and over time it develops a sense of place attachment in their life. Moreover, SC is rooted in their culture and tradition, and is a way of preserving their rich cultural traditions and diversity ${ }^{8}$. Some customs persist from generation to generation, like offerings to the Gods in case of good harvests from $\mathrm{SC}^{25,26}$. There are also many festivals celebrated in connection with SC in NE India ${ }^{27,28}$, which keep people closer to their traditional practices and allow them to develop social bonding. Researchers point to the importance of shared place meanings in building consensus and collective actions for transformation ${ }^{29}$. Thus, it is necessary to consider these nature and traditional bonds. We have to understand human-valued priority for landuse planning ${ }^{13}$ and adopt consistent environmental and conservation planning ${ }^{30}$.

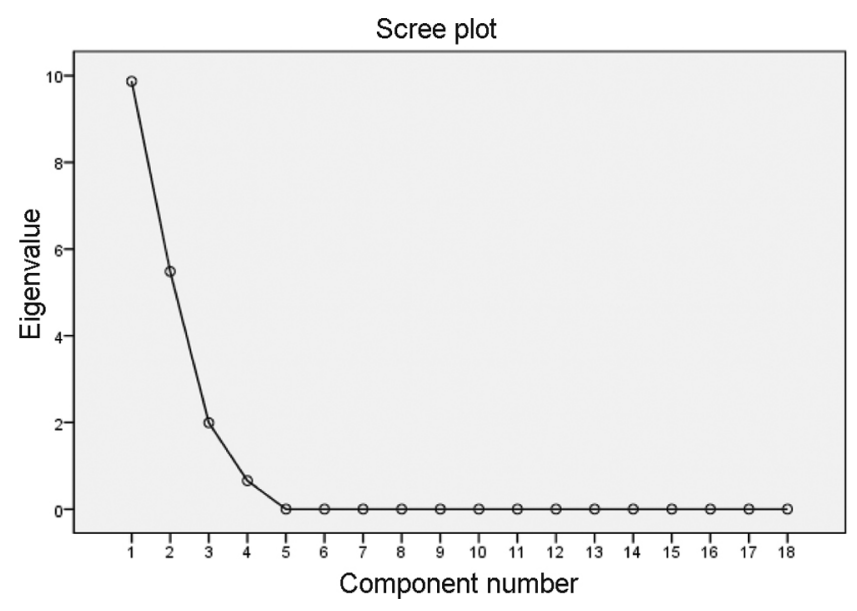

Figure 1. Fraction of total variance in the data as explained by each principal component. 


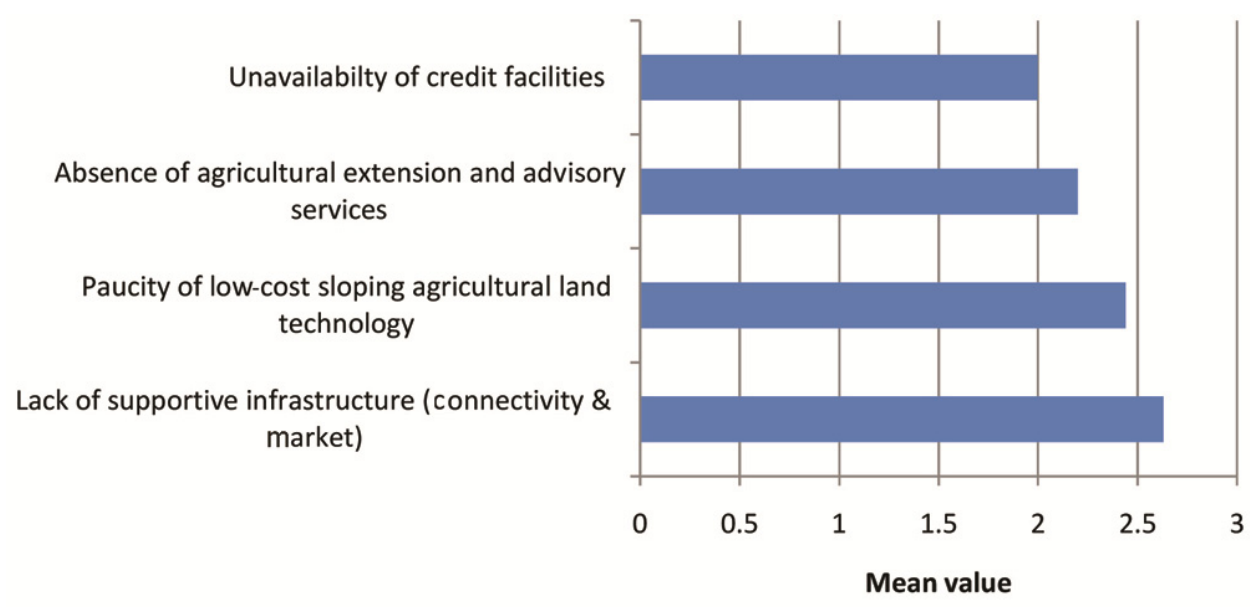

Figure 2. Factors governing attachment to shifting cultivation.

This study helps bridge the scholarships of sense of place and sustainability transitions in SC, with the aim to go beyond the trivial argument that 'place matters for sustainability transitions', to addressing what a placebased perspective and understanding contributes to making sense and design interventions for governance of rural sustainability transitions. With evidence from the case study and conceptual bridging of the two scholarships, it is contended that place becomes an attractor and a medium for sustainability of SC and other forest uses. It is empirically shown that sense of place, particularly place dependence is the major driver for persistence of the controversial practice of SC, while biophysical resources compel the hill tribes to continue the practice for livelihood security. Over the years, through informal experimentation, the tribes evolve alternative ways of utilizing the biophysical resources which is in harmony with their cultural settings for sustaining SC practice and deriving more support to their livelihood that would result in a deeper attachment to a particular place.

1. Pradheep, K., Pandey, A. and Bhatt, K. C., Wild edible plants used by Konyak tribe in Mon district of Nagaland: survey and inventorisation. Indian J. Nat. Prod. Resour., 2016, 7(1), 74-81.

2. Kuotsuo, R. U., Chatterjee, D. I., Deka, B. C., Kumar, R.A. A. O M. and Vikramjeet, K. O., Shifting cultivation: an 'organic like' farming in Nagaland. Indian J. Hill Farming, 2014, 27, 23-28.

3. Karmaker, R., Nagaland loses soil heavily due to 'jhum', 2018; https://www.thehindu.com/todays-paper/tp-national/tp-otherstates/ nagaland-loses-soil-heavily-due-to-jhum/article23552211.ece (accessed on 13 September 2018)

4. Pant, R. M., Tiwari, B. K. and Choudhury, D., Report of Working Group III, shifting cultivation: towards a transformational approach. NITI Aayog, New Delhi, 2018.

5. Fox, J., Castella, J. C. and Ziegler, A. D., Swidden, rubber and carbon: Can REDD+ work for people and the environment in Montane Mainland Southeast Asia? Global Environ. Change, 2014, 29, 318-326.

6. Asia Indigenous Peoples Pact Foundation and Indigenous Knowledge and Peoples Network, Who we are: Indigenous Peoples in Asia, Briefing Paper, Chiang Mai, AIPP Printing Press, 2010.
7. Rao, M. G., Mukherjee, C., Bhasin, A., Barua, A., Anand, M., Pandey, R. and Srinivasan, R., Vision document for the State of Meghalaya 2030. Nat. Institute of Public Finance and Policy, 2011; http://www.megplanning.gov.in/report/vision2030/ (accessed on 16 September 2018).

8. Erni, C., Shifting cultivation, livelihood and food security: new and old challenges for indigenous peoples in Asia. In Shifting Cultivation, Livelihood and Food Security, 2015, vol. 3.

9. Mertz, O. and Bruun, T. B., Shifting cultivation policies in Southeast Asia-does criminalizing traditional farming practices make them go away? In Shifting Cultivation Policy: Trying to Get it Right (ed. Cairns, M.), Earthscan Routledge Press, Oxon, UK, 2016.

10. Dressler, W. H., Wilson, D., Clendenning, J., Cramb, R., Keenan, R., Mahanty, S. and Lasco, R. D., The impact of swidden decline on livelihoods and ecosystem services in Southeast Asia: a review of the evidence from 1990 to 2015. Ambio, 2017, 46(3), 291-310.

11. Alawadi, K., Place attachment as a motivation for community preservation: the demise of an old, bustling, Dubai community. Urban Stud., 2017, 54(13), 2973-2997.

12. Anton, C. E. and Lawrence, C., The relationship between place attachment, the theory of planned behaviour and residents' response to place change. J. Environ. Psychol., 2016, 47, 145154.

13. Brown, G. and Raymond, C., The relationship between place attachment and landscape values: toward mapping place attachment. Appl. Geogr., 2007, 27(2), 89-111.

14. Raymond, C. M., Brown, G. and Weber, D., The measurement of place attachment: personal, community, and environmental connections. J. Environ. Psychol., 2010, 30(4), 422-434.

15. Pearson, Karl, On lines and planes of closest fit to systems of points in space. Philos. Mag., 1901, 2(11), 559-572.

16. Hammitt, W. E., Backlund, E. A. and Bixler, R. D., Place bonding for recreation places: Conceptual and empirical development. Leisure Stud., 2006, 25(1), 17-41.

17. Pant, M., Nagaland State Human Development Report 2016, Department of Planning and Coordination, Government of Nagaland, 2016 (accessed on 29 October 2018).

18. Tynsong, H., Tiwari, B. K. and Dkhar, M., Contribution of NTFPs to cash income of the War Khasi community of southern Meghalaya, North-East India. For. Stud. China, 2012, 14(1), 47-54.

19. Padoch, C., Coffey, K., Mertz, O., Leisz, S. J., Fox, J. and Wadley, R. L., The demise of swidden in Southeast Asia? Local realities and regional ambiguities. Geogr. Tidsskr.-Dan. J. Geogr., 2007, 107(1), 29-41. 
20. Mishra, S., Mazumdar, S. and Suar, D., Place attachment and flood preparedness. J. Environ. Psychol., 2010, 30(2), 187-197.

21. Fernandes, W., Look (act) East policy: with or through the Northeast. In Mainstreaming the Northeast in India's Look and Act East Policy, Palgrave Macmillan, Singapore, 2018, pp. 233-251.

22. Tripathi, P., Tribes and forest: a critical appraisal of the tribal forest right in India. Res. J. Soc. Sci. Manage., 2016, 6(6), 1-8.

23. Singh, B. P., Biodiversity, tribal knowledge and life in India. Environ. Soc. Psychol., 2017, 2(1), 1-10.

24. Chaudhry, P., Dollo, M., Bagra, K. and Yakang, B., Traditional biodiversity conservation and natural resource management system of some tribes of Arunachal Pradesh, India. Interdiscip. Environ. Rev., 2011, 12(4), 338-348.

25. Das, S., and Das, M., Shifting cultivation in Tripura - a critical analysis. J. Agric. Life Sci., 2014, 1(1), 48-54.

26. Lombi, P., People's perception about shifting cultivation - with special reference to the Galo tribe of West Siang District, Arunachal Pradesh (India). Int. J. Sci. Res. Publ., 2016, 6(7), 454-459.

27. Sangma, R. C., Festivals and ceremonies of Garo. Garo J., 2018; https://garojournal.com/festivals-ceremonies-garos/ (accessed on 23 October 2018)

28. Teegalapalli, K. and Datta, A., Shifting to settled cultivation: changing practices among the Adis in central Arunachal Pradesh. North-East India. Ambio, 2016, 45(5), 602-612.

29. Chapin III, F. S. (eds). Arctic Ecosystems in a Changing Climate: An Ecophysiological Perspective, Academic Press, San Diego, California, 2012.

30. Raymond, C. M. et al., Ecosystem services and beyond: using multiple metaphors to understand human-environment relationships. BioScience, 2013, 63(7), 536-546.

ACKNOWLEDGEMENTS. This study was conducted as part of the project 'Mapping of socio-economic and livelihood patterns of Jhumias in North Eastern Hill Region of India', funded by the Indian Council of Agricultural Research, New Delhi. We thank all the respondents, tribals and key informants for their cooperation.

Received 19 November 2018; accepted 10 January 2019

\section{Did Romans have direct maritime trade contacts with Odisha on the Eastern Indian littoral?}

\author{
Sila Tripati* and Rudra Prasad Behera \\ CSIR-National Institute of Oceanography, Dona Paula, \\ Goa 403 004, India
}

Kalinga, Utkal, Odra and Orissa are former names of the present state of Odisha with varied geographical boundaries in different periods of history. The exploration and excavations of Manikapatna, Palur, Radhanagar, Sisupalgarh, Talapada of Odisha have

\footnotetext{
*For correspondence. (e-mail: sila@nio.org)
}

brought to light terracotta Roman bullae with Roman portraits, lamps, amphorae shreds and rouletted ware which suggested that these findings belong to the Roman period (early centuries of Christian era) and Roman mariners had maritime contacts with Odisha from the early historical period onwards, if not earlier. However, it is evident that Roman artefacts such as gold coins, amphorae, Terra Sigillata (Arretine ware), etc., are more abundant in peninsular India than in the rest of the country and these findings are limited in Odisha, but the reasons are not comprehensible. However, archaeological findings from the port and trade centres delineate maritime contacts of Odisha with Southeast Asian countries. Here we discuss the archaeological findings from the port sites of Odisha to understand the maritime contacts with Southeast Asian countries and the Roman Empire and examine why the Roman findings are comparatively less in Odisha than in peninsular and other parts of India.

Keywords: Odisha, maritime trade, ports, Romans, Southeast Asia.

THE recorded history of Odisha, east coast of India, starts from the 3 rd century BCE onwards. In the annals of history, Odisha has been referred to as Udra or Odra Desa, Kalinga, Utkal, Orissa; now it has been renamed as Odisha. Archaeological findings, epigraphic, sculptural, literary and art evidence corroborate the maritime contacts of Odisha with Southeast Asian countries and the Roman Empire. However, the contacts between Odisha and Southeast Asia are more evident compared with those of the Roman Empire. Earlier studies ${ }^{1-5}$ suggest maritime contacts of Odisha with the Roman empire, Roman findings in Odisha, etc. Therefore, it is crucial to understand whether Odisha had direct trade contacts with the Roman Empire or not, and why the Roman findings are very limited in Odisha compared with peninsular India. As a result, in this study, the archaeological findings such as different types of pottery, amphorae, Roman coins, etc., found from ports and settlement sites of Odisha and neighbourhood are examined to understand the contacts between Odisha and the Roman Empire. An attempt has also been made to understand the reasons why Roman findings were limited in Odisha.

In the Indian Ocean maritime trade, during the early historical period, a wide variety of pottery was recorded from ports and trade centres along the east and west coasts of India. Pottery is a well preserved cultural material which can be traced along with other maritime trade materials, and it was one of the objects and medium used for the trade. The early historical period pottery namely Northern black polished ware (NBPW), rouletted ware (RW), knobbed ware (KW), stamped ware, amphorae and other artefacts were transported both by land and water routes. The discovery of identical pottery from a number 